\title{
Application of Prandtl's Theory in the Design of an Experimental Chamber for Static Pressure Measurements
}

\author{
Pavla Šabacká $^{1,2}$, Vilém Neděla ${ }^{1} \mathbb{D}$, Jiří Maxa ${ }^{1,2, * \mathbb{C}}$ and Robert Bayer ${ }^{2}$ \\ 1 Institute of Scientific Instruments of the CAS, 61264 Brno, Czech Republic; xhlava44@vutbr.cz (P.Š.); \\ vilem@isibrno.cz (V.N.) \\ 2 Department of Electrical and Electronic Technology, Brno University of Technology, \\ 61100 Brno, Czech Republic; xbayer02@vut.cz \\ * Correspondence: maxa@feec.vutbr.cz
}

Citation: Šabacká, P.; Neděla, V.; Maxa, J.; Bayer, R. Application of Prandtl's Theory in the Design of an Experimental Chamber for Static Pressure Measurements. Sensors 2021, 21, 6849. https://doi.org/10.3390/ s21206849

Academic Editor: Chelakara S. Subramanian

Received: 19 August 2021

Accepted: 12 October 2021

Published: 15 October 2021

Publisher's Note: MDPI stays neutral with regard to jurisdictional claims in published maps and institutional affiliations.

Copyright: (c) 2021 by the authors. Licensee MDPI, Basel, Switzerland. This article is an open access article distributed under the terms and conditions of the Creative Commons Attribution (CC BY) license (https:// creativecommons.org/licenses/by/ $4.0 /)$.

\begin{abstract}
Pumping in vacuum chambers is part of the field of environmental electron microscopy. These chambers are separated from each other by a small-diameter aperture that creates a critical flow in the supersonic flow regime. The distribution of pressure and shock waves in the path of the primary electron beam passing through the differentially pumped chamber has a large influence on the quality of the resulting microscope image. As part of this research, an experimental chamber was constructed to map supersonic flow at low pressures. The shape of this chamber was designed using mathematical-physical analyses, which served not only as a basis for the design of its geometry, but especially for the correct choice of absolute and differential pressure sensors with respect to the cryogenic temperature generated in the supersonic flow. The mathematical and physical analyses presented here map the nature of the supersonic flow with large gradients of state variables at low pressures at the continuum mechanics boundary near the region of free molecule motion in which the Environmental Electron Microscope and its differentially pumped chamber operate, which has a significant impact on the resulting sharpness of the final image obtained by the microscope. The results of this work map the flow in and behind the Laval nozzle in the experimental chamber and are the initial basis that enabled the optimization of the design of the chamber based on Prandtl's theory for the possibility of fitting it with pressure probes in such a way that they can map the flow in and behind the Laval nozzle.
\end{abstract}

Keywords: ESEM; BD sensor; static probe; static pressure; mach number; differentially pumped chamber; Prandtl's theory

\section{Introduction}

Currently, the Department of Electrical and Electronic Engineering of the Brno University of Technology in cooperation with the Institute of Instrumentation Technology of the Academy of Sciences of the Czech Republic in Brno is conducting research on environmental electron microscopy with a focus on the field of vacuum pumped chambers, and particularly on differentially pumped chambers and chambers for samples that are separated by a small diameter aperture, which causes a critical flow in the supersonic regime ending in a shock wave. The pressure and shock wave distribution in the primary path of the electron beam passing through the differentially pumped chamber has a great influence on the resulting image quality [1-3]. The environmental scanning electron microscope (ESEM) is one of the most promising tools for studying plant [4-6] and polymer $[7,8]$ samples using special signal electron detectors [9], which were developed based on gas flow simulations.

The experimental chamber is currently being completed. This experimental chamber has been designed to simulate the flow condition in the aperture region between the sample chamber and the differentially pumped chamber, between which there is normally a pressure difference of $100 \mathrm{~Pa}$ to $2000 \mathrm{~Pa}$. It was necessary to perform mathematical and 
physical analyses because of the planned measurement of flow pressures, velocities and temperatures in that region of the supersonic flow at low pressures. The objective of this work was to perform the necessary analyses to determine the final shape of the Laval nozzle using Prandtl's theory and to evaluate the flow condition in and behind the nozzle to determine the appropriate shape and position of the Pitot tube and temperature probe.

At the beginning of these low-pressure studies, it was necessary to compare the Monte Carlo method with the continuum mechanics method. This comparison was published in the paper Comparisons Using Methods of Continuum Mechanics and Monte Carlo at Differentially Pumped Chamber [10].

Comparison of the Monte Carlo simulation results with those obtained using ANSYS Fluent shows that both methods provide similar results [10]. On the basis of this study, which confirmed the possibility of using Ansys Fluent to map the flow at the limit of continuum mechanics, a model of the experimental chamber was designed, the shape of which allows the use of probes utilizing Prandtl's theory.

Membrane sensors will be used to measure the pressures on the walls of the Laval nozzle and in the chambers in a configuration that will operate reliably at the expected pressures while meeting high measurement accuracy and avoiding their overloading.

\section{Experimental Chamber}

The designed experimental chamber for mapping the pressure at the limit of continuum mechanics consists of two chambers separated by a small aperture, simulating the condition occurring during differential pumping. In the aperture, under these conditions, a critical flow is generated, manifested by a so-called nozzle clogging, beyond which a supersonic flow is generated with a low-pressure region ending in a specific shock wave [11]. The designed chamber allows the exchange of the aperture, which will make it possible to experimentally analyze different aperture shapes. It also includes a sliding mount for different types of measuring devices (Figure 1). This chamber was manufactured at the Institute of Scientific Instruments and loaned to the Department of Electrical and Electronic Technology of the Brno University of Technology, where it is currently being assembled. Finally, the chamber is also equipped with two visors through which it will be possible to observe and analyze the investigated area of flow and shock waves using the Schlieren method.
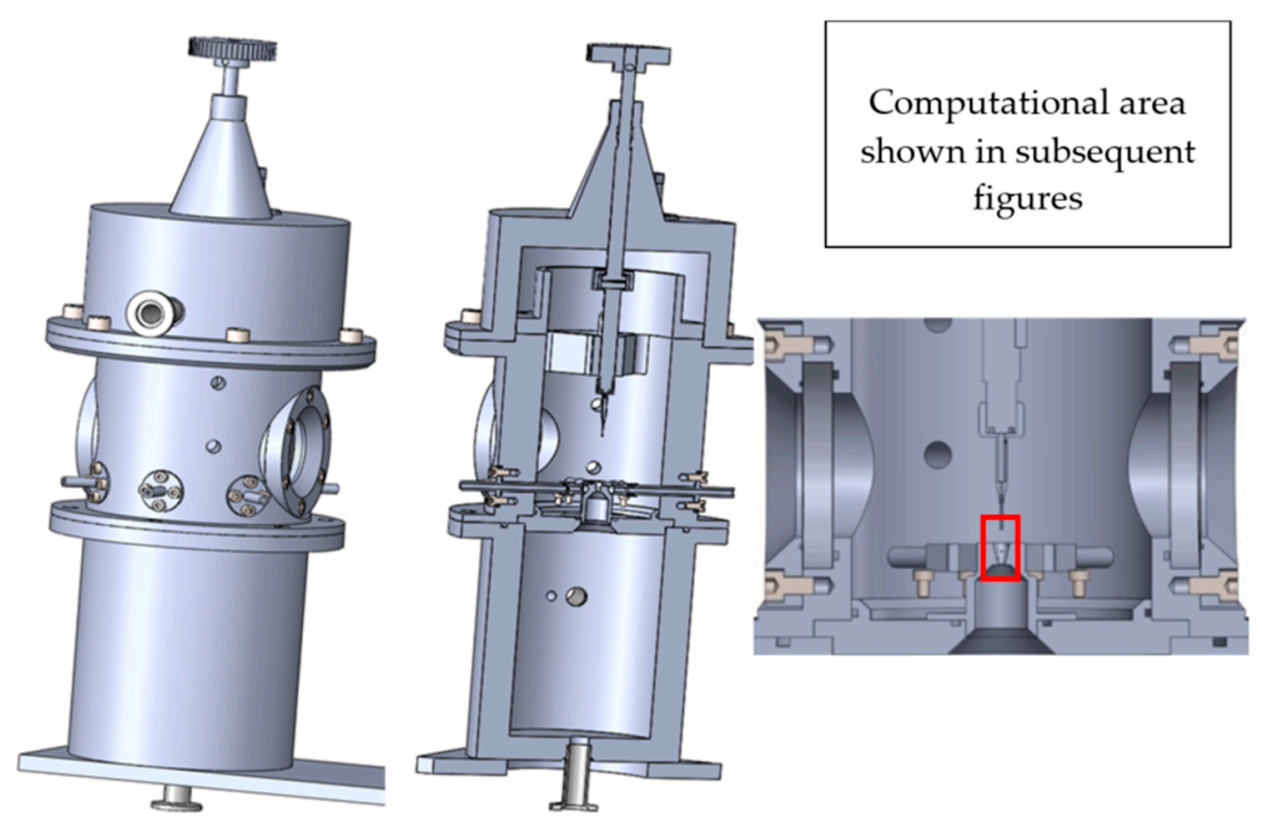

Figure 1. Experimental chamber. 
These measurements are planned in several stages in this experimental chamber:

- Measurement of the flow velocity using a Pitot tube,

- Measurement of the pressure in the primary electron beam path,

- Temperature measurements in the supersonic flow region using a thermocouple,

- Analysis of the supersonic flow by the Schlieren optical method.

For these measurements, interchangeable holders will be used for different probe mountings for pressure and temperature measurements.

Due to the difference in the diameter of the aperture $(2 \mathrm{~mm})$ and the experimental chamber itself $(80 \mathrm{~mm})$, it will not be possible to construct the Pitot tube in one piece, but the static pressure and total pressure will be measured separately.

\section{Flow Analyzes in the Experimental Chamber}

The mathematical-physics analyses of the flow in the experimental chamber in Ansys Fluent system were used as a base for its own construction [12]. The layouts for static pressure, total pressure, velocity, Mach number, and temperature were mapped in the area of the whole chamber but primarily in the area of supersonic flow $[13,14]$. This has a great impact on the scattering of the primary beam when passing through the Differentially pumped chamber $[15,16]$.

A cross-section of the experimental chamber is shown in Figure 2. An axisymmetric calculation has been performed, which allows the calculation to be accelerated due to the assumption of axisymmetry of the flow [17]. In Figure 3, the path along which other variables were calculated is marked in blue. In general, the entire chamber will be mapped for pressure and temperature, but a particular emphasis will be placed on the supersonic flow and the mapping of the nozzle and the flow behind it $[18,19]$.

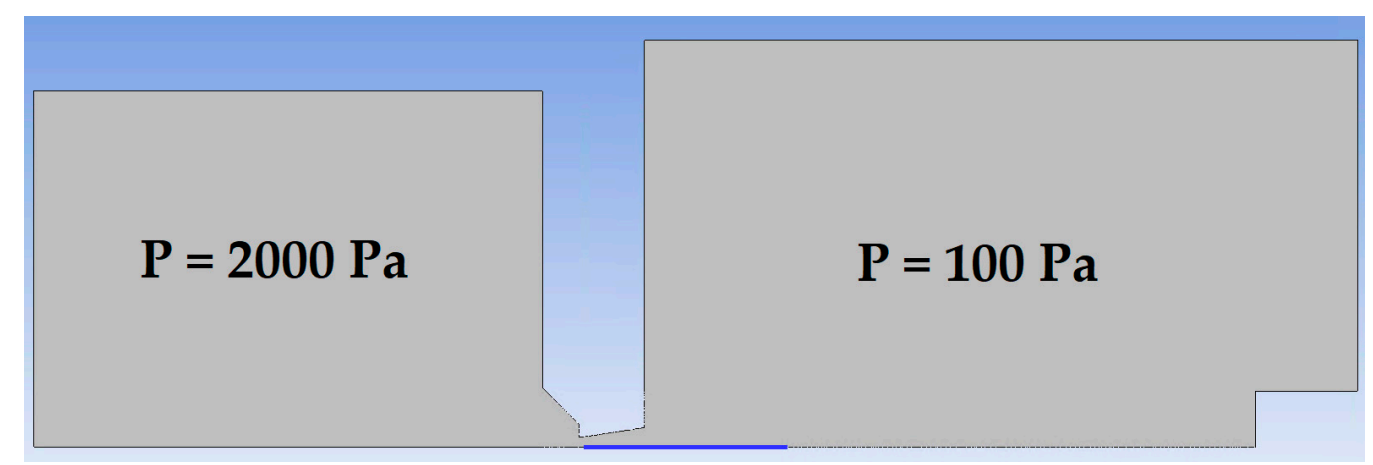

Figure 2. Cross-section through the experimental chamber in the aperture area.

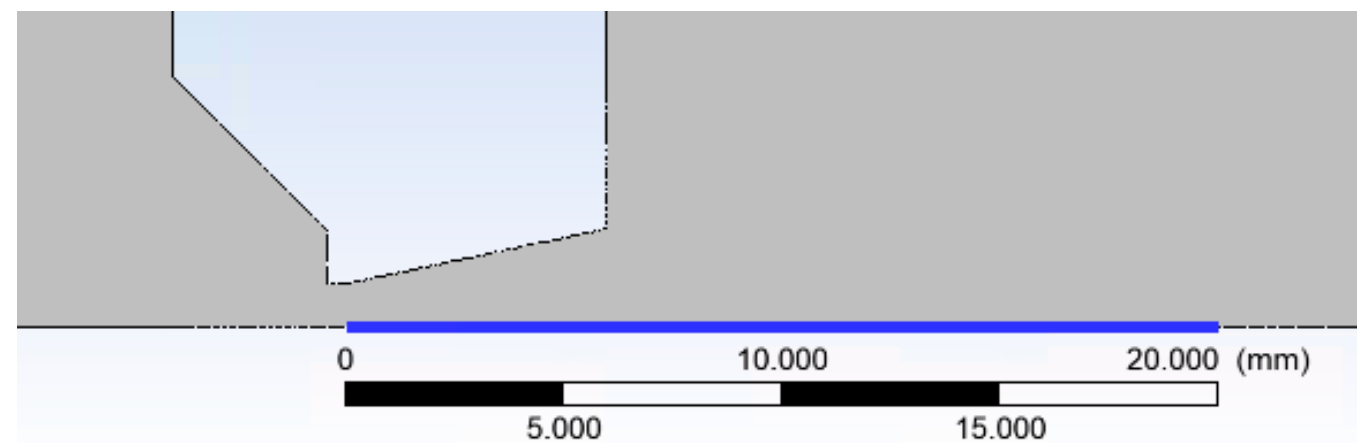

Figure 3. Cross-section through the experimental chamber in the aperture area (detail).

The simulation used continuum mechanics, where the Ansys Fluent system uses the Navier-Stokes equations, which are second-order partial nonlinear differential equations. These equations cover all aspects of real fluid behavior including turbulence. The given equations have been solved using the finite volume method. 
Due to the compressibility of the flow and the assumption of high-pressure gradients associated with supersonic flow, a density-based fluid density solver was used. In this particular case, we used an implicit formulation where the unknown values are given by the existing values and also the unknown values of the neighboring cells. We also used the Advection Upstream Splitting Method (AUSM), which is more suitable for solving supersonic flow. For discretization, we used the second-order method.

As in this case, it is a very low-pressure environment, it is necessary to check the value of the Knudsen number to see if it is still a continuous environment.

To map the Knudsen number in a dimensionally various space, a method that has been successfully published by the FOM Institute for Plasma Physics Rijnhuizen and the Department of Applied Physics, Eindhoven University of Technology [20] was used.

The Knudsen number can be checked according to:

$$
K n=\frac{\lambda}{L}
$$

where $\lambda$ is the mean free path of gas molecules and $L$ is the characteristic dimension [20].

For the mean free path, the following applies:

$$
\lambda=\frac{k T}{\sqrt{2} \pi \delta^{2} p}
$$

where $k$ is the Boltzmann constant, $T$ is the absolute temperature, $\delta$ is the gas molecule diameter and $p$ is the pressure.

According to [21], the calculation of the characteristic dimension $L$ as Density/Density Gradient was performed.

The distribution of Knudsen number is shown in Figure 4:

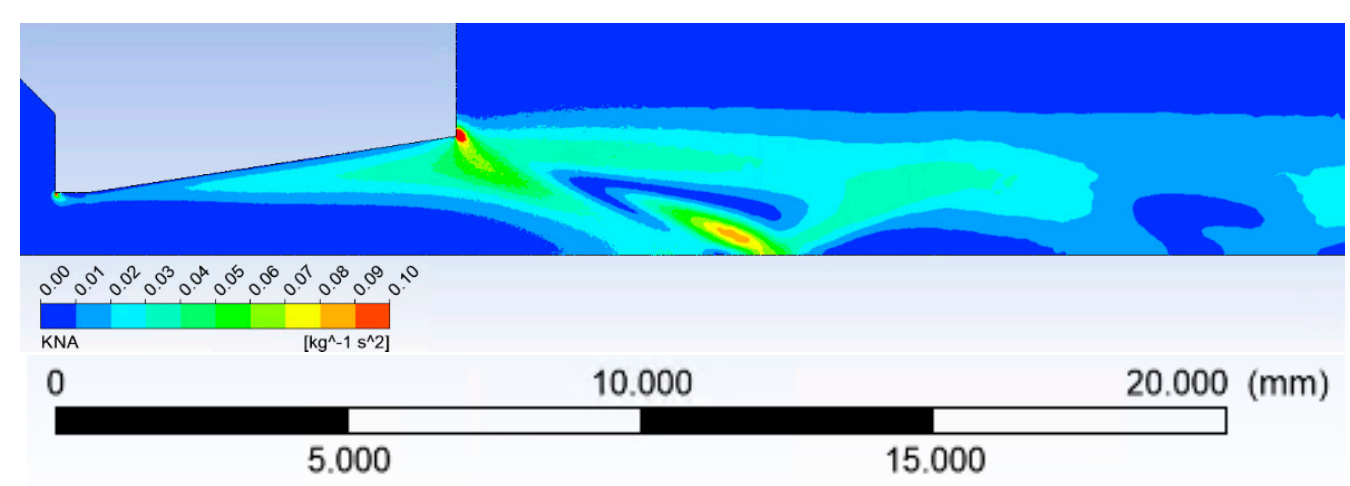

Figure 4. The distribution of the Knudsen number.

With respect to the Knudsen number, the calculation was solved in Slip Flow mode. The findings published in [21,22] were used for the first setting of the Shear stress on the wall for the Slip Flow model and its subsequent debugging.

The design principle of the experimental chamber described below is based on the experience and work of Dr. Danilatos.

As in [3], a comparison was made between the results obtained with Ansys Fluent and the results published by Dr. Danilatos in the field of thin aperture [23,24] and the results for the conical aperture. The findings published by Dr. Danilatos in [24] in the field of nozzle opening angle selection are followed in this paper in a different way, where the shape of the nozzle cone is determined by the Expansion cross-section calculation.

Dr. Danilatost often maps flow in narrow spaces that are typical for certain types of differential pumping [25]. In dimensionally small chambers, the supersonic flow has the character of an elongated cone and each additional even a smaller narrowing act as an additional aperture. Therefore, for the investigated case, the chamber behind the nozzle was designed in such a way that the supersonic flow was not affected in any way and the 
subsequent mathematical and physical analyses then showed no effect of even reflected shock waves on the gas flow in the path of the primary electron beam.

\section{Static Pressure Measurement According to Prandtl's Theory}

As already mentioned, the classical Pitot tube for static pressure measurement does not allow to capture the pressure in the nozzle, but only in the area above the nozzle, due to the small size of the chamber. Therefore, a different measurement method was used. This involves the elimination of static pressure using small holes spirally arranged around the circumference of the nozzle outlet based on Prandtl's theory, according to which the static pressure distribution in the flow cross-section has equal values. This applies, for example, to laminar flow through a pipe. In a supersonic flow behind the nozzle throat, the gas expands in such a way that the exact shape of the nozzle can be assumed based on the calculated cross-section when applying Prandtl's theory (Figure 5).

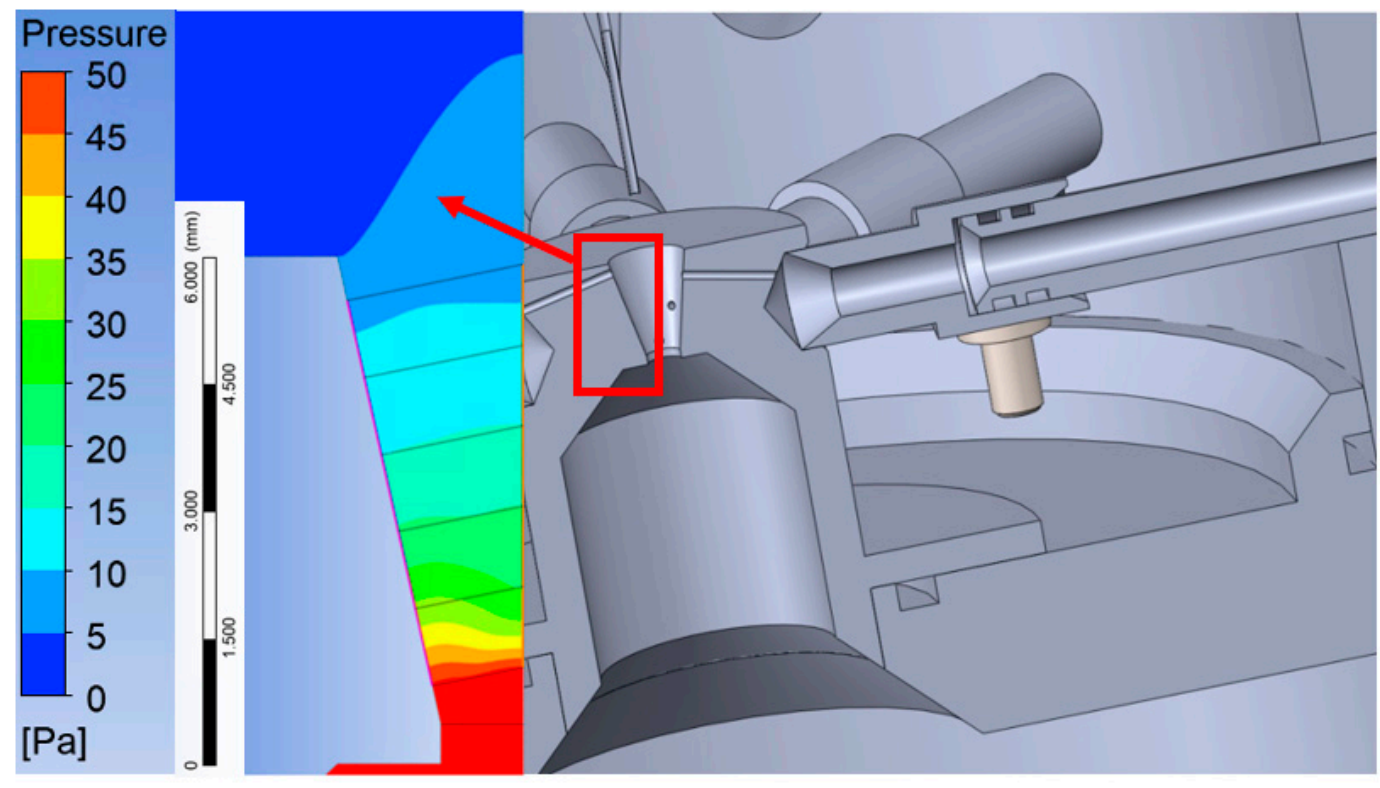

Figure 5. The shape of the conical Laval nozzle for Prandtl's theory.

The most accurate shape which copies the gas expansion is the Laval nozzle. This can be constructed in three ways: characteristic method, linear shape, or Bell nozzle (Figures 6-8) [7]. Due to the production technology, the most advantageous construction is based on linear shape (Figure 8).

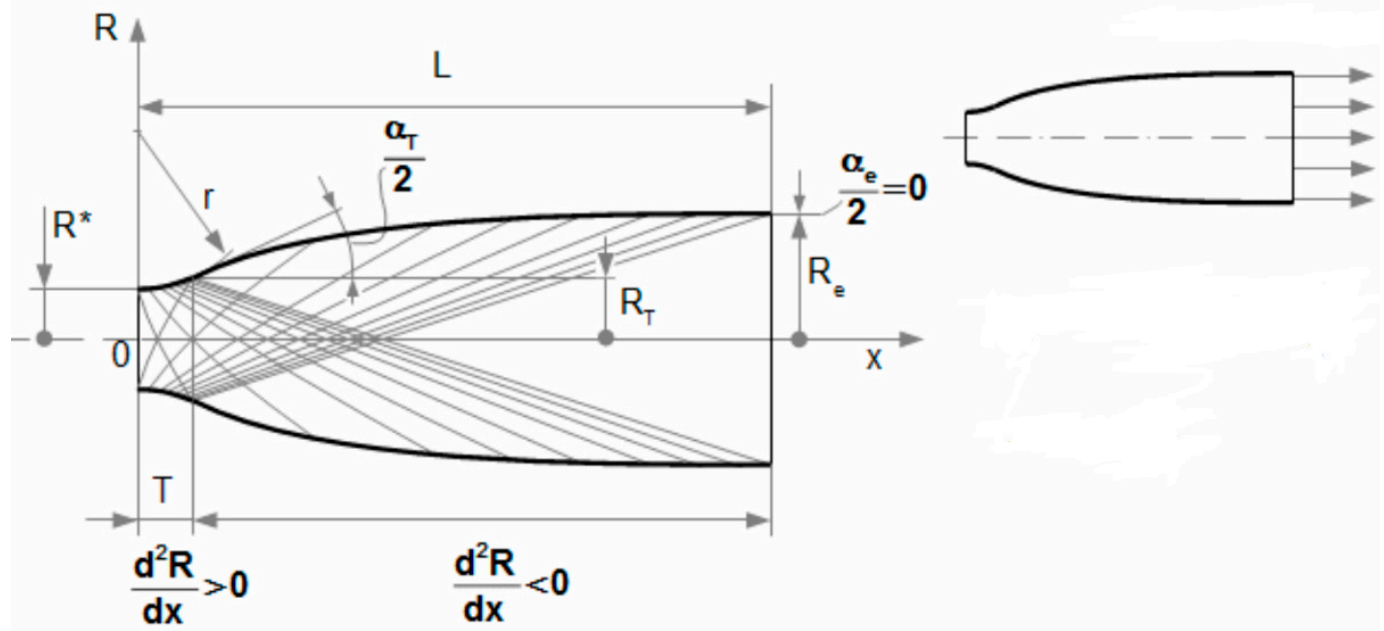

Figure 6. Laval nozzle—characteristic method. Reprinted from ref. [26]. 


$$
\begin{gathered}
r_{t}=r^{*}+r_{r}\left(1-\cos \frac{\alpha_{1}}{2}\right) \\
t=r_{r} \cdot \sin \frac{\alpha_{1}}{2} \\
\left(\frac{d r}{d x}\right)_{t}=\tan \frac{\alpha_{1}}{2},\left(\frac{d v}{d x}\right)_{e}=\tan \frac{\alpha_{2}}{2} \\
I=t+\frac{r_{e}-r_{t}}{\operatorname{tg} \frac{\alpha}{2}}
\end{gathered}
$$
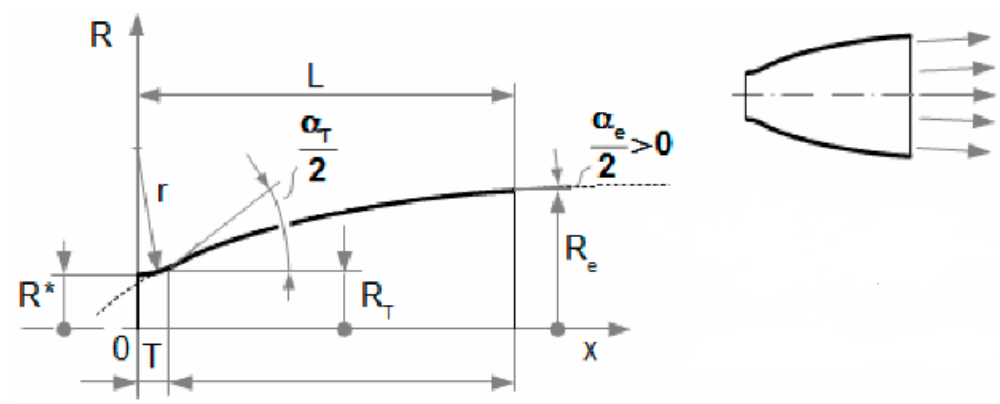

Figure 7. Laval nozzle-Bell nozzle. Reprinted from ref. [26].
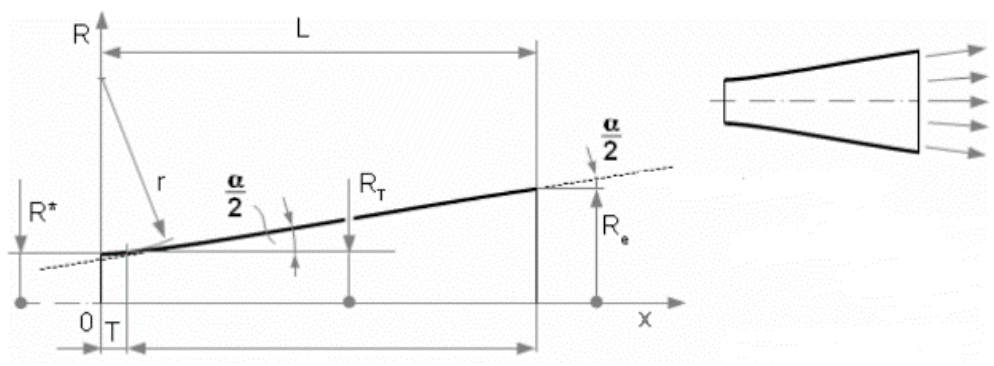

Figure 8. Laval nozzle-Linear shape. Reprinted from ref. [26].

The calculation of the gas expansion dimensions, which is based on the shape of the Laval nozzle, was determined based on the physics of the isentropic one-dimensional flow. This leads to relationships that determine the relationship of pressures, densities, velocities, and Mach numbers between the inlet area of the nozzle, within the nozzle, and the calculated gas expansion cross-section behind the nozzle [27].

For isentropic flow, the following applies:

$$
\begin{aligned}
& \frac{v_{v}}{v_{k r}}=\left[\frac{(\varkappa+1) M^{2}}{2+(\varkappa-1) M^{2}}\right]^{\frac{1}{2}} \\
& \frac{v_{v}}{v_{o}}=\left[\frac{2}{2+(\varkappa-1) M^{2}}\right]^{\frac{1}{2}} \\
& \frac{T_{v}}{T_{o}}=\frac{2}{2+(\varkappa-1) M^{2}} \\
& \frac{p_{v}}{p_{o}}=\left[\frac{2}{2+(\varkappa-1) M^{2}}\right]^{\frac{\varkappa}{\varkappa-1}} \\
& \frac{\rho_{v}}{\rho_{o}}=\left[\frac{2}{2+(\varkappa-1) M^{2}}\right]^{\frac{1}{\varkappa-1}}
\end{aligned}
$$




$$
\frac{\rho_{v}}{\rho_{k r}}=\frac{A_{k r}}{A}=M\left[\frac{\varkappa+1}{2+(\varkappa-1) M^{2}}\right]^{\frac{1}{2} \frac{\varkappa+1}{\varkappa-1}}
$$

where $p_{0}$ is the input pressure, $p_{v}$ is the output pressure, $T_{0}$ is the input temperature, $T_{v}$ is the output temperature, $v_{0}$ is the input velocity, $v_{v}$ is the output velocity, $v_{k r}$ is the critical velocity, $\rho_{0}$ is the input density, $\rho_{v}$ is the output density, $M$ is the Mach number, is the gas constant $=1.14, A$ is the computational cross-section and $A_{k r}$ is the critical cross-section.

This computational cross-section $(A)$ of the Laval nozzle was determined based on the above calculations. At these six points (Figure 9), the temperature and total pressure will be measured using probes placed on the axis, and according to Prandtl's theory, the static pressure will be captured from the walls where the pressure distribution is assumed to be the same in both the projection and the axis.

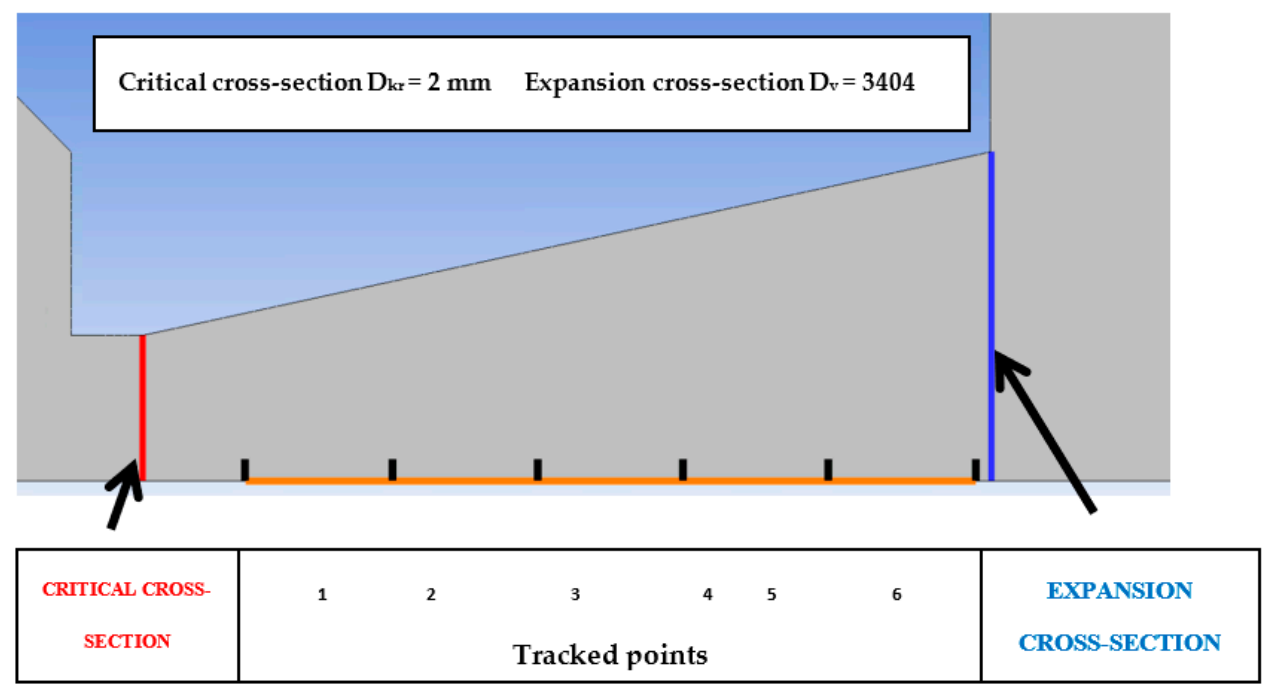

Figure 9. Measured points.

The pressure ratio $p_{o}=2000 \mathrm{~Pa}$ and $p_{v}=100 \mathrm{~Pa}$ are based on the given relations and the results are shown in Table 1:

Table 1. Calculated values in critical input cross-section [28].

\begin{tabular}{ccccccc}
\hline $\begin{array}{c}\text { Mach } \\
\text { Number }\end{array}$ & $\begin{array}{c}\text { Output } \\
\text { Velocity/Critical } \\
\text { Velocity }\end{array}$ & $\begin{array}{c}\text { Output } \\
\text { Velocity/Input } \\
\text { Velocity }\end{array}$ & $\begin{array}{c}\text { Output Tempera- } \\
\text { ture/Input } \\
\text { Temperature }\end{array}$ & $\begin{array}{c}\text { Output } \\
\text { Pressure/Input } \\
\text { Pressure }\end{array}$ & $\begin{array}{c}\text { Output } \\
\text { Density/Input } \\
\text { Density }\end{array}$ & $\begin{array}{c}\text { Output } \\
\text { Density/Critical } \\
\text { Density }\end{array}$ \\
\hline$M_{v}$ & $v_{v} / v_{k r}$ & $v_{v} / v_{0}$ & $T_{v} / T_{0}$ & $p_{v} / p_{0}$ & $\rho_{v} / \rho_{0}$ & $\rho_{v} / \rho_{k r}$ \\
2.6 & 1.8571 & 0.6521 & 0.4252 & 0.05 & 0.1179 & 0.3453 \\
\hline
\end{tabular}

In addition, the speed of sound at the input in the given environment is determined from relation 8 and equals $346.7 \mathrm{~ms}^{-1}$ :

$$
v_{0}=\sqrt{\chi R T_{0}}
$$

where $R$ is the universal gas constant and $T_{0}=297.15 \mathrm{~K}$.

In Table 1 , the ratio of $\rho_{v} / \rho_{0}=0.0617$. Then, it is possible to determine the value of output density $\rho_{v}=0.00276 \mathrm{~kg} \cdot \mathrm{m}^{-3}$.

After the mathematical and physical analyses in Ansys Fluent, a back check was performed according to the physics of one-dimensional flow for the calculated crosssection. The values obtained theoretically were compared with the values obtained using Ansys Fluent and the measurement errors are minimal in this case.

The values of $v_{v}, \rho_{0}, \rho_{v}$ and $T_{v}$ were used as control values for the results obtained with Ansys Fluent (Table 2). 
Table 2. Results of comparison of Ansys values with one-dimensional flow theory.

\begin{tabular}{ccc}
\hline & Theoretical Value & Ansys Fluent Value \\
\hline Mach number $(-)$ & 2.6 & 2.598 \\
Density $\left(\mathrm{kg} \cdot \mathrm{m}^{-3}\right)$ & 0.00276 & 0.00265 \\
Velocity $\left(\mathrm{m} \cdot \mathrm{s}^{-1}\right)$ & 585.8 & 582 \\
Temperature $\left({ }^{\circ} \mathrm{C}\right)$ & 126.3 & 126.8 \\
\hline
\end{tabular}

Then, the size of the nozzle opening or the so-called computational cross-section can be determined, where Prandtl's theory applies, so that the static pressure is the same throughout the cross-section.

For a given density ratio $\rho_{v} / \rho_{k r}$, which is shown in Table 1 , the following applies:

$$
\frac{\rho_{v}}{\rho_{k r}}=\frac{A_{k r}}{A_{v}}=0.3453
$$

For the selected hole diameter $D_{k r}=2 \mathrm{~mm}$, the value $A_{k r}=3.14 \mathrm{~mm}^{2}$. From relation 10 , the calculated cross-section is equal to $A_{v}=9.1 \mathrm{~mm}^{2}$, and therefore $D_{v}=3.4 \mathrm{~mm}$. The angle of $12^{\circ}$ was determined according to [29].

The results of Dr. Danilatos [10] were used to analyze the location of the Mach disk under the given low-pressure conditions:

$$
z_{M}=0.67 D_{k r} \sqrt{\frac{P_{0}}{P_{1}}}=6 \mathrm{~mm}
$$

With a nozzle length of $5.941 \mathrm{~mm}$, the distance of the Mach disk is approximately $12 \mathrm{~mm}$ from the critical cross-section. Subsequent analysis of the ANSYS Fluent results showed the same Mach disk distance (Figure 10), with experience with Mach disk placement also drawn from [30].

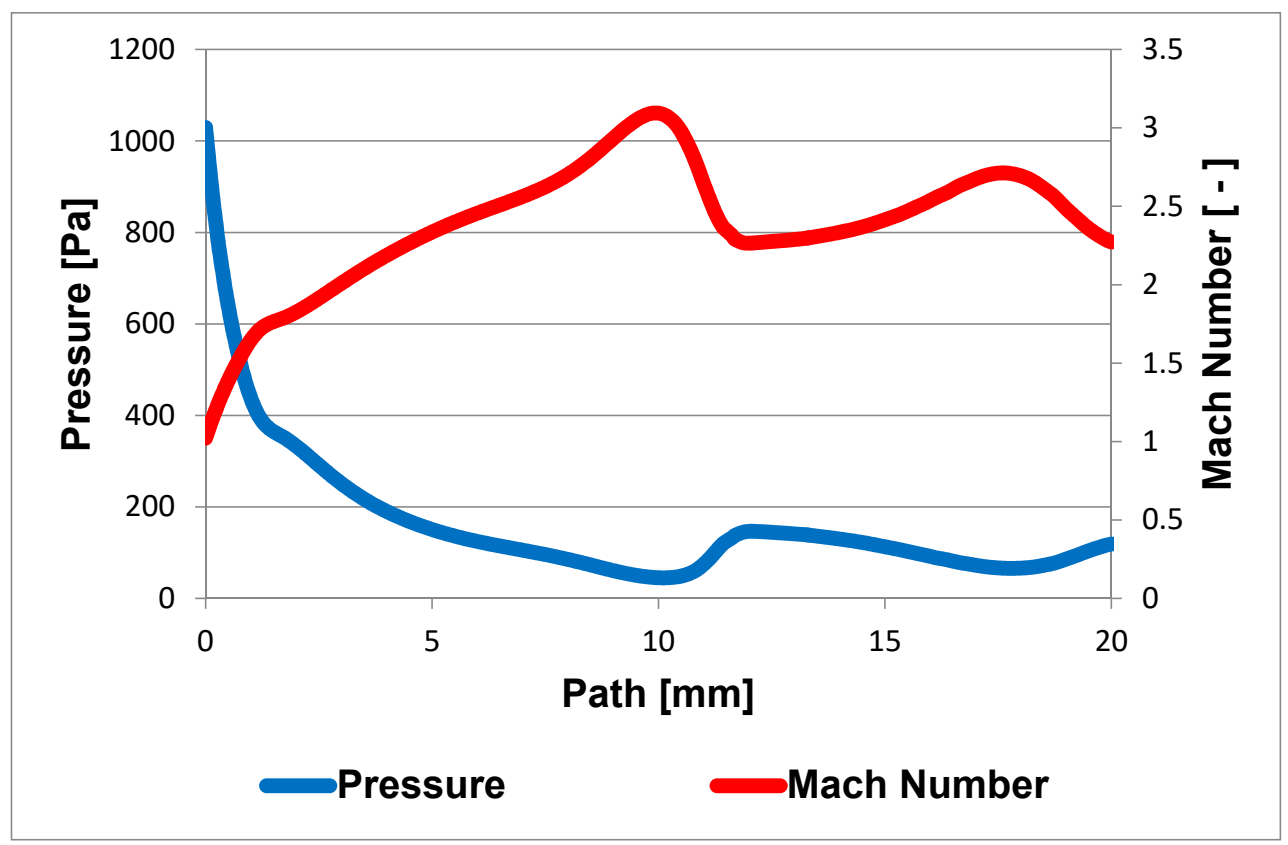

Figure 10. Pressure and Mach number on the path shown in Figure 3.

Figure 10 shows the formation of two Mach disks at distances of $12 \mathrm{~mm}$ and $19 \mathrm{~mm}$ from the critical section. This will result in a decrease in flow velocity and an increase in pressure compared to the region beyond the critical section or behind the Mach disk, behind which a region of low pressure and therefore high flow velocity is created due to 
particle entrainment by the ambient flow. From Figure 11, it can be seen that the measured points were selected according to Prandtl's theory, according to which the holes were spirally arranged along the nozzle exit cone, and whose perpendicular projection points to these selected points. At the same time, according to the first calculations of the static pressure distribution in the nozzle, it can be seen that Prandtl's theory is correctly applied. However, in the region of the second measured point, the pressure distribution is slightly rotated precisely because of the chosen technologically simpler linear shape of the nozzle.

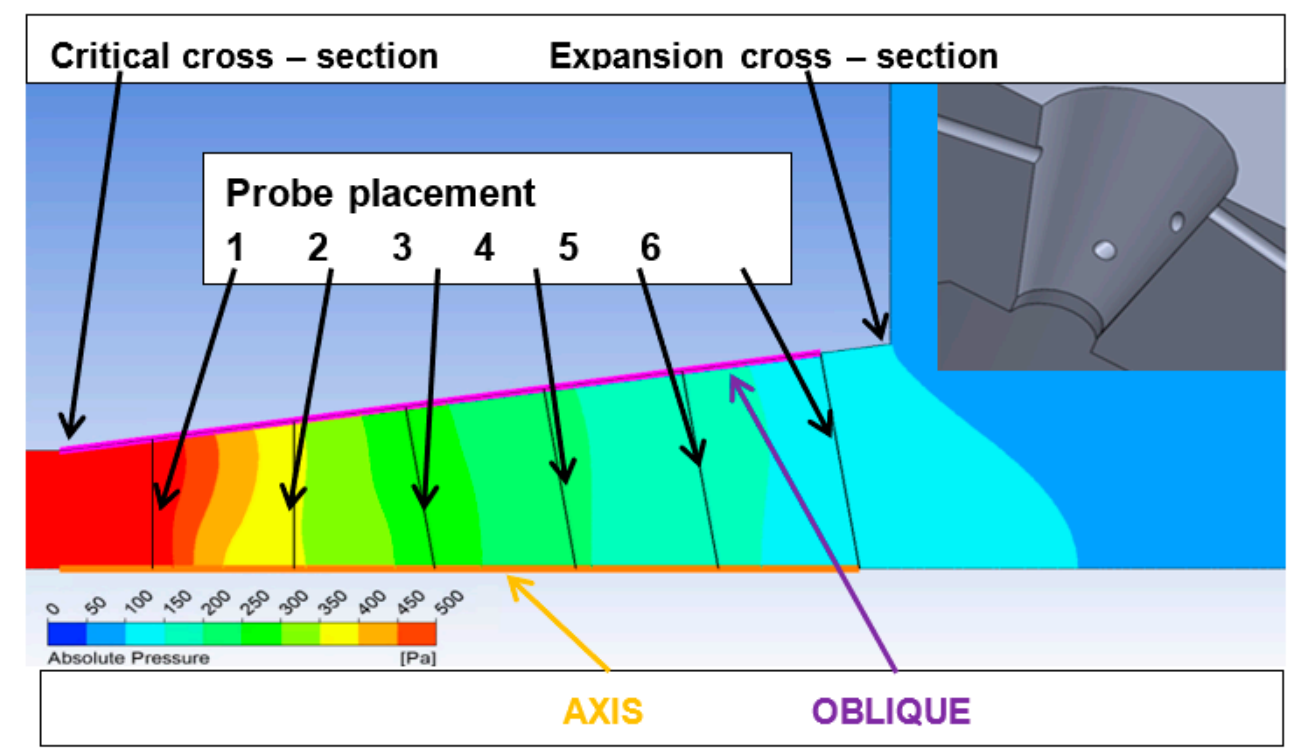

Figure 11. Designed linear nozzle with measuring points for probe placement.

Comparing the pressure profile, it is clear from Figure 12 that the differences are minimal. However, at points 1 and 2, the pressure profile is rotated due to the perpendicularity of the holes to the axis to simplify the shape of the Laval nozzle.

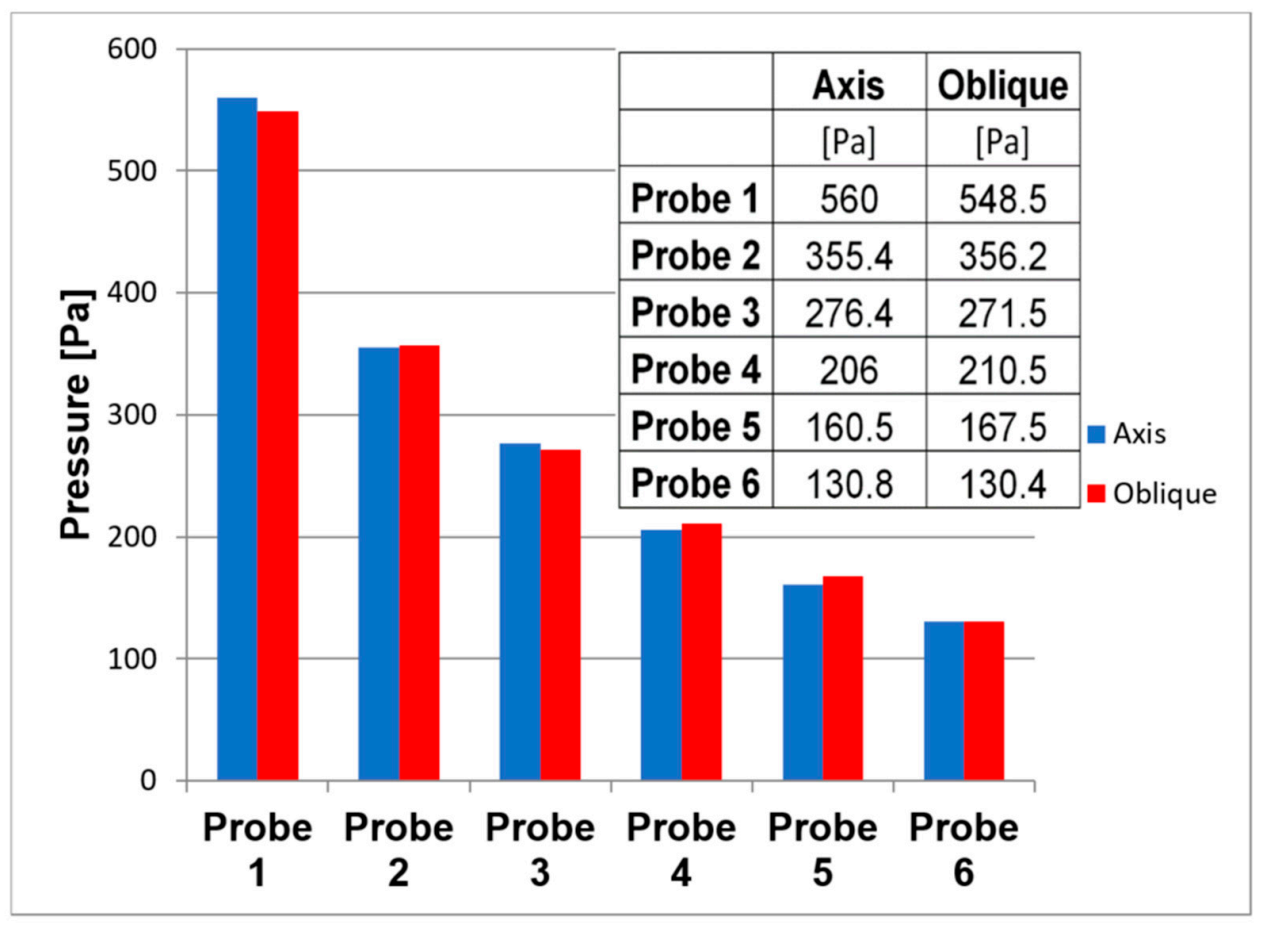

Figure 12. Comparison of static pressure on the axis and oblique surface of the nozzle according to Prandtl's theory. 


\section{Use of a Membrane Pressure Difference Sensor for Low Pressures Measurements}

Using the mathematical and physical analyses above, it was found that the pressure distribution in the two chambers separated by the Laval nozzle corresponds to the pressure distribution in the nozzle itself. As a result, pressure differences between the planned pressure measurement points were also found [31]. Figure 13 shows a diagram of the distribution of measurement points in the experimental chamber with the pressures at the probe outlets marked.

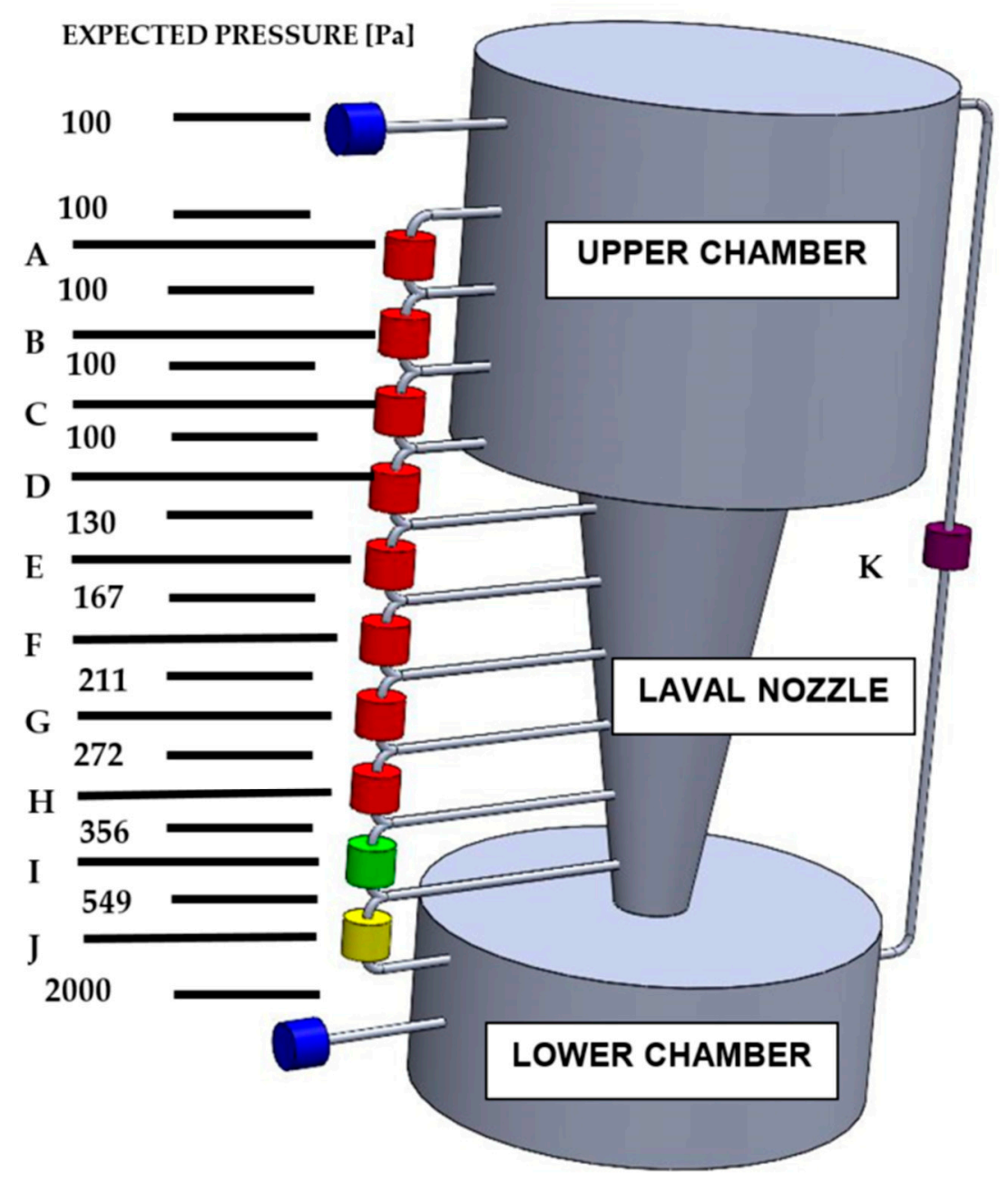

Figure 13. Probe placement on the experimental chamber.

From these predicted measured pressures, the expected pressure difference at the pressure probes is calculated, see Table 3 .

Table 3. The expected pressure difference in the pressure probes.

\begin{tabular}{ccccccccccc}
\hline PROBE & A & B & C & D & E & F & G & H & I & J \\
\hline $\begin{array}{l}\text { EXPECTED } \\
\text { PRESSURE }\end{array}$ & $0-5$ & $0-5$ & $0-5$ & 30 & 37 & 44 & 61 & 84 & 193 & 1451 \\
DIFFERENCE (Pa) & & & & & & & & & & \\
\hline
\end{tabular}

Figure 13 is for illustrative purposes only. For better illustration, the Laval nozzle separating the two chambers is shown here enlarged disproportionately to its surroundings. The correct ratio of the sizes of the Upper and Lower Chambers and the Laval nozzle can be seen in Figures 1 and 2. The distance between points $\mathrm{A}$ and $\mathrm{H}$ (the two counterpoints of 
the probes with the finest resolution) is $68 \mathrm{~mm}$. Due to the above-mentioned illustrative nature of Figure 13, it should be pointed out that the spacing of the probes E, F, G and H, which map the pressure distribution in the Laval nozzle, are $1 \mathrm{~mm}$, while the spacing of the probes $A, B, C$ and D, which map the pressure distribution in the upper chamber, are $20 \mathrm{~mm}$.

The upper and lower chambers are measured with absolute manometers to measure the absolute pressure in both chambers. However, between the two chambers, only differential pressure gauges are connected in series.

The selected differential pressure sensor is a DPS 300 from BD Sensors. The DPS+ differential pressure sensor was developed for the measurement of dry non-aggressive gases and compressed air. The basic element of the DPS+ is a piezoresistive pressure sensor with temperature compensation, which is able to operate for a very long time without any maintenance. The Robust design also allows deployment in the laboratory and industrial environments. The DPS+ pressure sensor is characterized by excellent long-term stability, linearity and repeatability. Therefore, it is suitable for our experiment [32,33].

Given the values shown in Table 3, the following variants of the PCB 300 probes will be used:

- For probe J: differential pressure value $4000 \mathrm{~Pa}$.

- For probe I: differential pressure value $400 \mathrm{~Pa}$.

- For probes A-H: differential pressure value $160 \mathrm{~Pa}$.

The measurement error for the probes is the following:

- $\quad$ For the range below $600 \mathrm{~Pa} \pm 0.5 \%$ of the range.

- For the range above $600 \mathrm{~Pa} \pm 1 \%$ of the range.

At key points on the surface of the Laval nozzle where the pressure difference between the sensors is $30 \mathrm{~Pa}$, the measurement error will be $0.8 \mathrm{~Pa}$.

The principle of measurement will be that the absolute gauges will read the absolute pressures in the upper and lower chambers and monitor the error that occurs in the differential probe series.

Once the desired pressure ratio of $2000 \mathrm{~Pa}$ in the upper chamber and $100 \mathrm{~Pa}$ in the lower chamber is reached, the differential sensors will be connected as they cannot be connected when pumping from atmospheric pressure because they would be damaged by overloading. Once the differential gauges are connected, the differential pressures will be measured.

At the same time, the pressure difference between the two chambers shall be measured using probe $\mathrm{K}$ and the error of the difference between the absolute pressures measured by the absolute gauges and the pressure difference measured by the differential gauge between the two chambers shall be evaluated.

At the same time, the error of the sum of the individual differences measured by the differential gauges in series between the two chambers shall be evaluated.

The results will be compared with those obtained by mathematical and physical analysis from Ansys Fluent.

\section{Conclusions}

The paper is a follow-up to the comparative analyses carried out at the Institute of Electrical and Electronic Engineering FEEC BUT in cooperation with the Institute of Scientific Instruments of the CAS, v.v.i., where the possibility of using the Ansys Fluent system using continuum mechanics is compared with the analyses carried out in the Monte Carlo system of Dr. Danilatos. On the basis of these mathematical and physical analyses from Ansys Fluent, the design of an experimental chamber for supersonic flow at low pressures at the limit of continuum mechanics was realized. This experimental chamber will simulate the differential pumping conditions in the aperture region between the sample chamber and the differentially pumped chamber in an environmental scanning electron microscope. Since this is a very small space where conventional probes could not be placed, 
it was necessary to determine the final shape of the Laval nozzle according to Prandtl's theory by mathematical and physical analyses to measure unbiased pressure readings in the flow axis and from the nozzle wall.

The results of the mathematical-physical analyses applying Prandtl's theory, described in this paper, allowed the necessary corrections to be made to the geometry of the Laval nozzle inside the pumped chamber to measure the static pressure inside this nozzle by simplifying the shape of its opening while maintaining its properties.

The results of the analyses were also the basis for the selection of the type of absolute and differential pressure probes and temperature probes related to the cryogenic regime.

Without the information obtained from these analyses, several time- and cost-consuming experiments would have been needed.

Author Contributions: Conceptualization, P.Š. and V.N.; methodology, V.N.; software, P.Š. and J.M.; validation, J.M.; formal analysis, J.M.; investigation, P.Š.; resources, V.N.; data curation, J.M.; writing—original draft preparation, P.Š. and J.M.; writing—review and editing, R.B.; visualization, P.Š. and R.B.; supervision, J.M.; project administration, V.N.; funding acquisition, V.N. All authors have read and agreed to the published version of the manuscript.

Funding: This research was funded by Grant Agency of the Czech Republic, grant number GA 19-03909S.

Institutional Review Board Statement: Not applicable.

Informed Consent Statement: Not applicable.

Data Availability Statement: The data presented in this study are available on request from the corresponding author.

Conflicts of Interest: The authors declare no conflict of interest.

\section{References}

1. Tihlaříková, E.; Neděla, V.; Dordevic, B. In-situ preparation of plant samples in ESEM for energy dispersive x-ray microanalysis and repetitive observation in SEM and ESEM. Sci. Rep. 2019, 9, 1-8. [CrossRef]

2. Neděla, V.; Konvalina, I.; Oral, M.; Hudec, J. The Simulation of Energy Distribution of Electrons Detected by Segmental Ionization Detector in High Pressure Conditions of ESEM. Microsc. Microanal. 2015, 21, 264-269. [CrossRef]

3. Jirák, J.; Neděla, V.; Černoch, P.; Čudek, P.; Runštuk, J. Scintillation SE detector for variable pressure scanning electron microscopes. J. Microsc. 2010, 239, 233-238. [CrossRef] [PubMed]

4. Neděla, V.; Tihlaříková, E.; Hřib, J. The Low-Temperature Method for Study of Coniferous Tissues in the Environmental Scanning Electron Microscope. Microsc. Res. Tech. 2015, 78, 13-21. [CrossRef] [PubMed]

5. Neděla, V.; Hřib, J.; Vooková, B. Imaging of early conifer embryogenic tissues with the environmental scanning electron microscope. Biol. Plant. 2012, 56, 595-598. [CrossRef]

6. Schenkmayerová, A.; Bučko, M.; Gemeiner, P.; Trel'ová, D.; Lacík, I.; Chorvát Jr., D.; Ačai, P.; Polakovič, M.; Lipták, L.; Rebroš, M.; et al. Physical and Bioengineering Properties of Polyvinyl Alcohol Lens-Shaped Particles Versus Spherical Polyelectrolyte Complex Microcapsules as Immobilisation Matrices for a Whole-Cell Baeyer-Villiger Monooxygenase. Appl. Biochem. Biotechnol. 2014, 174, 1834-1849. [CrossRef]

7. Neděla, V.; Tihlaříková, E.; Maxa, J.; Imrichová, K.; Bučko, M.; Gemeiner, P. Simulation-based optimisation of thermodynamic conditions in the ESEM for dynamical in-situ study of spherical polyelectrolyte complex particles in their native state. Ultramicroscopy 2020, 211, 112954. [CrossRef]

8. Maxa, J.; Neděla, V.; Jirák, J.; Vyroubal, P.; Hladká, K. Analysis of gas flow in a secondary electron scintillation detector for ESEM with a new system of pressure limiting apertures. Adv. Mil. Technol. 2012, 7, 111-116.

9. Maxa, J.; Bílek, M.; Hlavatá, P.; Vyroubal, P.; Lepltová, K. Comparisons Using Methods of Continuum Mechanics and Monte Carlo at Differentially Pumped Chamber. Adv. Mil. Technol. 2016, 11, 143-150. [CrossRef]

10. Danilatos, G.D. Velocity and ejector-jet assisted differential pumping: Novel design stages for environmental SEM. Micron 2012, 43, 600-611. [CrossRef]

11. Thevenin, D.; Janiga, D. Optimization and Computational Fluid Dynamics; Springer: Berlin/Heidelberg, Germany, 2008.

12. Moran, M.; Shapiro, H. Fundamentals of Engineering Thermodynamics, 3rd ed.; John Wiley \& Sons, Inc.: New York, NY, USA, 1996.

13. Baehr, H. Thermodynamik, 14th ed.; Springer: Berlin, Germany, 2009.

14. Bilek, M.; Maxa, J.; Hlavata, P.; Bayer, R. Modeling and simulation of a velocity field within supersonic flows in low-pressure areas. ECS Trans. 2017, 81, 311-316. [CrossRef] 
15. Vyroubal, P.; Maxa, J.; Neděla, V.; Jirák, J.; Hladká, K. Apertures with Laval Nozzle and Circular Orifice in Secondary Electron Detector for Environmental Scanning Electron Microscope. Adv. Mil. Technol. 2013, 8, 59-69.

16. Neděla, V.; Tihlař́ková, E.; Runštuk, J.; Hudec, J. High-efficiency detector of secondary and backscattered electrons for low-dose imaging in the ESEM. Ultramicroscopy 2018, 184, 1-11. [CrossRef] [PubMed]

17. Maxa, J.; Neděla, V. The Impact of Critical Flow on the Primary Electron Beam Passage through Differentially Pumped Chamber. Adv. Mil. Technol. 2011, 6, 39-46.

18. Dejč, M.J. Technická Dynamika Plynů; SNTL: Prague, Czechoslovak Republic, 1967.

19. Uruba, V. Turbulence. Available online: http://www2.it.cas.cz/ \{\}uruba/docs/Aero/Turbulence_45.pdf (accessed on 12 October 2021).

20. Roy, S.; Raju, R. Modeling gas flow through microchannels and nanopores. J. Appl. Phys. 2003, 93, 4870-4879. [CrossRef]

21. Van Eck, H.J.N.; Koppers, W.R.; van Rooij, G.; Goedheer, W.J.; Engeln, R.; Schram, D.C.; Cardozo, N.J.L.; Kleyn, A.W. Modeling and experiments on differential pumping in linear plasma generators operating at high gas flows. J. Appl. Phys. 2009, 105, 063307. [CrossRef]

22. Liu, Q.; Feng, X.-B. Numerical Modelling of Microchannel Gas Flows in the Transition Flow Regime Using the Cascaded Lattice Boltzmann Method. Entropy 2020, 22, 41. [CrossRef]

23. Danilatos, G. Optimum beam transfer in the environmental scanning electron microscope. J. Microsc. 2009, 234, 26-37. [CrossRef]

24. Danilatos, G.D. Figure of merit for environmental SEM and its implications. J. Microsc. 2011, 244, 159-169. [CrossRef]

25. Danilatos, G.; Rattenberger, J.; Dracopoulos, V. Beam transfer characteristics of a commercial environmental SEM and a low vacuum SEM. J. Microsc. 2011, 242, 166-180. [CrossRef]

26. Škorpík, J. Proudění Plynů a par Tryskami. Available online: https://www.transformacni-technologie.cz/ (accessed on 12 October 2021).

27. Salga, J.; Hoření, B. Tabulky Proudění Plynu; UNOB: Brno, Czech Republic, 1997.

28. Bayer, R.; Maxa, J.; Šabacká, P. Energy Harvesting Using Thermocouple and Compressed Air. Sensors 2021, 21, 6031. [CrossRef] [PubMed]

29. Daněk, M. Aerodynamika a Mechanika Letu; VVLŠ SNP: Košice, Slovakia, 1990; p. 83.

30. Danilatos, G.D. Environmental scanning electron microscopy and microanalysis. Mikrochim. Acta 1994, 114, 143-155. [CrossRef]

31. Choi, E.; Kim, S.; Gong, J.; Sun, H.; Kwon, M.; Seo, H.; Sul, O.; Lee, S.-B. Tactile Interaction Sensor with Millimeter Sensing Acuity. Sensors 2021, 21, 4274. [CrossRef] [PubMed]

32. Kasai, M.; Sasaki, D.; Nagata, T.; Nonomura, T.; Asai, K. Frequency Response of Pressure-Sensitive Paints under Low-Pressure Conditions. Sensors 2021, 21, 3187. [CrossRef] [PubMed]

33. Drexler, P.; Čáp, M.; Fiala, P.; Steinbauer, M.; Kadlec, R.; Kaška, M.; Kočiš, L. A Sensor System for Detecting and Localizing Partial Discharges in Power Transformers with Improved Immunity to Interferences. Sensors 2019, 19, 923. [CrossRef] 